\title{
Editorial: Exploring Volcanic Paroxysmal Explosive Activity From Magma Source to Ground and Atmosphere
}

\author{
Sonia Calvari ${ }^{1 *}$, Alessandro Bonaccorso ${ }^{1}$, Clive Oppenheimer ${ }^{2}$ and Letizia Spampinato ${ }^{1}$ \\ ${ }^{1}$ Istituto Nazionale di Geofisica e Vulcanologia, Osservatorio Etneo - Sezione di Catania, Catania, Italy, ${ }^{2}$ Department of \\ Geography, University of Cambridge, Cambridge, United Kingdom
}

Keywords: explosive activity, paroxysm, ash plume, volcanoes, Etna volcano, geophysical data, gas geochemistry, satellite remote sensing

Editorial on the Research Topic

Exploring Volcanic Paroxysmal Explosive Activity From Magma Source to Ground and Atmosphere

Volcanic paroxysmal explosive activity has enormous potential destructive power and usually causes widespread damages to the Society (NAS-National Academies of Sciences Engineering Medicine, 2017). Serious problems can occur even during explosive activity related to modest eruptions, such as the case of the 2010 Eyiafjallajokull eruption in Iceland that paralyzed the air traffic in the European continent and in the North Atlantic. In general, a crucial issue, and also an intriguing challenge, is to evaluate the state of the preparatory phase leading to an eruption. It is important to understand the characteristics of the volcano state both for the long-term preparatory phases, usually anticipating the strongest eruptions, and also for the medium- to short-term phases preceding the more frequent and usually less powerful eruptions, but with more immediate consequences.

The first paper of the collection gives an overview of the long-term dynamics of the volcanic paroxysmal activity at andesitic and dacitic volcanoes during 1960-2010 (Zobin). In this study two groups of eruptions with VEI 5-6 and VEI 3-4 were considered. The main tool used was the seismic monitoring of the volcanoes. The eruptions of the first group are characterized by long periods of quiescence (longer than 120 years) and precursory volcano tectonic seismic swarms. The second group develops in more individual styles, each typical of a certain volcano. The study suggests that the eruptions with higher VEI are related to a plugged magmatic conduit, whereas eruptions with lower VEI are usually associated to open conduits.

As a specific case of volcano producing frequent explosive eruptions with low VEI, the second paper of this Research Topic considers the Etna eruptive activity during 2009-2017 by using ground deformation and strain data (Aloisi et al.). Etna volcano was characterized over this period by an incredible lively eruptive activity. This comprised 44 lava fountain episodes from the New South East Crater, two sequences of lava fountains from the Voragine crater, as well as some periods of summit effusive activity with a more prolonged supply of lava flows. The authors produced a complete representation of the different sources that characterized the different periods both in the medium-term (i.e., the preparatory phases showing inflation and the eruptive phases showing deflation) and in the short-term (i.e., the fast discharge associated with eruptive events).

Ganci et al. investigated the middle-term behavior of Mt. Etna. Detection of the thermal anomalies allowed retrieval of radiative power time-series and associated volumes, and thus characterization of each of the paroxysms in terms of intensity and magnitude. Topographic data 
derived from satellite imagery gave the total volume of products erupted from 2005 to 2015. Overall, the integration of thermal and topographic data highlighted that the 2011-2012 lava fountains had higher intensity than those of 2013-2015 and that the total volumes erupted from 2005 to 2015 resulted being below those typically erupted by Mt. Etna in a decadal time scale.

Recent eruptive activity from Etna offered a great opportunity to measure the $\mathrm{SO}_{2}$ gas flux from ground-based and satellite instruments prior to, during and after the paroxysmal sequences (D’Aleo et al.), allowing to detect the switch from an active crater to another on the basis of increased and decreased $\mathrm{SO}_{2}$ flux. Based on these measurements, the degassed magma volume was estimated, leading to inferring on the fraction of erupted magma compared to the amount emplaced into the shallow feeding system. Another important parameter essential for hazard assessment is Mass Eruption Rate (MER), which has been estimated for 47 paroxysmal episodes using a Doppler Radar installed on Etna (Freret-Lorgeril et al.). The Lidar detection of the volcanic plume, volcanic ash concentration in atmosphere, and characterization of optical properties of volcanic particles, represent the distal characterization of the paroxysmal activity, essential for modeling volcanic ash clouds and their impact (Boselli et al.).

Mapping of the erupted products and measurement and retrieval of the main eruptive parameters are crucial to understand the eruptive dynamics and investigate into the volcano shallow feeder system. Nowadays, volcanology can take advantage from different measurement techniques and methodologies spanning from direct field observations to ground- and satellite-based remote sensing. Indeed, the opportunity to inspect volcanic phenomena by multidisciplinary approaches allows getting overall view of the volcanic scenarios. The study of the tephra fallout produced by the 3 March 2015 lava fountain at Villarrica basaltic-andesitic volcano by field surveys, laboratory analysis, and satellite imagery provided characterization and parameterization of the paroxysm (Romero et al.). The integration of the key constraints shaded light in the mechanism that triggered the paroxysmal explosion in a volcano that commonly shows persistent activity associated to lava lake-like dynamics. At Mt. Etna, the multidisciplinary approach permitted the study of the recent paroxysmal activity at the volcano summit at both short- and long-time scale. Andronico et al. focused on the 25-26 October 2013 lava fountain. Using field observations and ground- and satellite-based imagery and photogrammetry, they mapped the lava flow field and estimated the volume of the pyroclastic cone. Mapping of the fallout deposit in field and laboratory analysis gave grain size distribution, composition, and total erupted mass.

The hazards posed by explosive activity is a function of the size of the eruption and of the elevation reached by the eruptive column and ash plume, that may impact the atmosphere or even the stratosphere and affect aviation, infrastructures, viability, climate, and health. The Volcanic Explosivity Index (VEI; Newhall and Self, 1982) is a way to estimate the size of an explosive eruption, with a VEI 6 posing severe hazard all over the country and a VEI 2-4 having only local effects. The last two papers of this collection evaluate the hazard posed by two end-member eruptions, such as the VEI 6 potential for Öræfajökull volcano in Iceland (Barsotti et al.) and the VEI 2-4 of Etna volcano in Sicily (Calvari et al.). Barsotti et al. use a numerical model to assess the impact on infrastructures in Iceland caused by a rare but potentially highly destructive activity occurring at the Öræfajökull volcano, which experienced this event only once during the last 1100 years. Etna instead has experienced hundreds of mild VEI 2-4 eruptions during the last decades, and Calvari et al. statistically analyze several of these events to propose an empirical law that allows them to evaluate the maximum elevation of an ash plume as soon as the lava fountain height has reached the peak steady value, measured using the images recorded by the monitoring thermal camera network.

Most of the papers comprised in this collection pertain to Mt. Etna, which has been identified as Decade Volcano by the International Association of Volcanology and Chemistry of the Earth's Interior (IAVCEI), thus confirming itself as an ideal volcano laboratory (Bonaccorso et al., 2004). The empirical laws thus far proposed for predicting the extension and impact of the eruptive clouds (Calvari et al.) are thus applicable just to this volcano, and in the future a greater effort has to be dedicated to multidisciplinary studies involving more volcanoes and cross-analyses of their data (e.g., Zobin) in order to obtain general statements, laws and/or formulas that could be applicable to those volcanoes which are less monitored. More peculiar and still unknown processes could arise from in depth studies of other basaltic volcanoes from the Earth and other planets, increasing our ability to understand and predict their behavior. A growing attention is dedicated to the use of UAV (unmanned aerial vehicles; e.g., Neri et al., 2017; Favalli et al., 2018), remote-sensing (Boselli et al.; Calvari et al.; D’Aleo et al.; Freret-Lorgeril et al.) and satellite measurements (Ganci et al.) for their safety issues, low cost and broad perspective, that result in an important integration of field studies (Andronico et al.; Romero et al.), numerical simulations (Barsotti et al.), and laboratory experiments (e.g., Dellino et al., 2010). It is a general feeling that the innovative methods will grow even more in the future, possibly coupled with virtual reality, allowing results and simulations of volcanic processes impossible to imagine nowadays.

\section{AUTHOR CONTRIBUTIONS}

All authors listed have made a substantial, direct and intellectual contribution to the work, and approved it for publication. 


\section{REFERENCES}

Bonaccorso, A., Calvari, S., Coltelli, M., Del Negro, C., and Falsaperla, S. (eds.). (2004). "Mt. Etna: volcano laboratory," in American Geophysical Union, Geophysical Monograph Series, v. $143: 350$

Dellino, P., Dioguardi, F., Zimanowski, B., Büttner, R., Mele, D., LaVolpe, L., et al. (2010). Conduit flow experiments help constraining the regime of explosive eruptions. J. Geophys. Res. 115:B04204. doi: 10.1029/2009JB0 06781

Favalli, M., Fornaciai, A., Nannipieri, L., Harris, A., Calvari, S., and Lormand, C. (2018). UAV-based remote sensing surveys of lava flow fields: a case study from Etna's 1974 channelfed lava flows. Bull. Volcanol. 80:29. doi: 10.1007/s00445-0181192-6

NAS-National Academies of Sciences Engineering and Medicine (2017). Volcanic Eruptions and Their Repose, Unrest, Precursors, and Timing. Washington, DC: The National Academies Press.
Neri, M., De Maio, M., Crepaldi, S., Suozzi, E., Lavy, M., Marchionatti, F., et al. (2017). Topographic maps of mount Etna summit crater's area, 14 december 2015. J. Maps 13, 674-683. doi: 10.1080/17445647.2017.1352041

Newhall, C. G., and Self, S. (1982). The volcanic explosivity index (VEI): an estimate of explosive magnitude for historical volcanism. J. Geophys. Res. 87, 1231-1238. doi: 10.1029/JC087iC02p01231

Conflict of Interest Statement: The authors declare that the research was conducted in the absence of any commercial or financial relationships that could be construed as a potential conflict of interest.

Copyright (c) 2019 Calvari, Bonaccorso, Oppenheimer and Spampinato. This is an open-access article distributed under the terms of the Creative Commons Attribution License (CC BY). The use, distribution or reproduction in other forums is permitted, provided the original author(s) and the copyright owner(s) are credited and that the original publication in this journal is cited, in accordance with accepted academic practice. No use, distribution or reproduction is permitted which does not comply with these terms. 